\title{
Next Waves In The Evolution Of Management Education: Non-Traded Enterprises And Spatial Awareness
}

\author{
Jerry Platt, University of Redlands, USA
}

\begin{abstract}
The last generation in management education identified and addressed two perceived gaps in standard degree curricula: global business and corporate ethics. The Association for Advancement of Collegiate Schools of Business (AACSB) has been instrumental in assuring these topics receive due attention. Given the current state of management education for the challenges of the $21^{\text {st }}$ century, what are the two gaps that are likely to be perceived and addressed during the next generation? The conjecture here is that attention to non-traded enterprises and to spatial awareness will emerge as critical components of management education in the near future, and will endure because their relevance and relative value will increase over time. Such a shift will necessitate substantial rethinking of curricula: more than 99\% of American businesses are "small", but the standard objective function taught in b-schools today is maximization of shareholder wealth, usually measured by changes in stock price. Similarly, the current estimate is that at least $80 \%$ of all business transactions or decisions involve a spatial component, yet this component rarely is explicitly recognized in today's b-school classes. The blurring of boundaries and increasing joint ventures among public, not-for-profit, corporate, and small-to-medium enterprises (SMEs), coupled with advancements in geographic information systems (GIS), suggests an impetus for these next two waves in management education. This paper provides background information and a projected trajectory for infusion of these concepts into tomorrow's curriculum.
\end{abstract}

Keywords: Business School, Small Business, SME, Not-for-Profit, Spatial Analysis, GIS

\section{INTRODUCTION}

¿ received my MBA long ago, in 1970. At that time, at the business school I attended and I suspect at most others as well, there were required courses in functional disciplines like marketing, accounting and finance - but it was quite possible to earn the degree without any exposure to either global business or corporate ethics. At that time, it seemed to me that international business was thought a rather esoteric concept, perhaps of value if one were to deal with imports and exports, but hardly a subject of serious inquiry. Unknown to me at the time, one school saw it differently: Thunderbird was a small and struggling independent school at the time, but bet its future on its belief that all business is global business - today the Thunderbird School of Global Management often is ranked among the best b-schools. A similar story can be told of business ethics, a topic that received absolutely no attention in the program I attended. The Association for Advancement of Collegiate Schools of Business (AACSB) has been instrumental in assuring these topics receive due attention. Given the current state of management education for the challenges of the $21^{\text {st }}$ century, what are the two gaps that are likely to be perceived and addressed during the next generation? Following are my two prime candidates.

\section{NON-TRADED ENTERPRISES}

It is not surprising that schools of business focus on business education. However, it is somewhat surprising that schools of management often focus exclusively on business education, even though many 
management principles apply as well to many non-business enterprises, including not-for-profit organizations and governmental agencies. Approximately one-third of the more than 500 schools accredited by The Association for Advancement of Collegiate Schools of Business (AACSB) list "Management" rather than "Business" in their school identification, including highly-ranked programs like the Kellogg Graduate School of Management (Northwestern University), the Sloan School of Management (MIT), and the Johnson School of Management (Cornell University). Nonetheless, there usually is no discernible difference in the attention afforded non-market enterprises, and that level of attention often is quite minimal. Some universities supplement traditional business degree offerings with programs in public administration or public affairs, either within the same school as the business programs or elsewhere on campus; many do not. Furthermore, business curriculum invariably assumes a large corporate structure, and instructors addressing critical issues like valuation simply assume the existence of efficiently priced securities traded in liquid markets. The reality is that most people do not work in public-traded corporations, and management education needs to change to reflect the growing trend toward non-traditional work environments, especially self-employment, small businesses, social entrepreneurship, and not-for-profit organizations. For specificity, the remainder of this section focuses on small businesses.

The table below (2) indicates that most business is small business. Of nearly six million firms registered in the United States, less than $0.3 \%$ have more than 500 employees, about 9 of 10 have less than 20 employees, and 2 of 3 have less than five employees.

\begin{tabular}{|c|c|c|c|c|c|}
\hline & \multicolumn{5}{|c|}{ Registered U.S. Non-Government Establishments, 2005} \\
\hline \multirow{3}{*}{$\begin{array}{l}\text { Employment } \\
\text { size of firm }\end{array}$} & \multirow[b]{3}{*}{ Firms } & & & \multirow{2}{*}{\multicolumn{2}{|c|}{ Annual Payroll }} \\
\hline & & & & & \\
\hline & & Establishments & Employment & $(\$ 1,000)$ & \\
\hline Total & $5,983,546$ & $7,499,702$ & $116,317,003$ & $\$ 4,482,722,481$ & \\
\hline \multirow[t]{2}{*}{$<5$} & $3,677,879$ & $3,684,047$ & $5,936,859$ & $220,009,104$ & \\
\hline & $61.5 \%$ & $49.1 \%$ & $5.1 \%$ & $4.9 \%$ & \\
\hline \multirow[t]{2}{*}{$<20$} & $5,357,887$ & $5,409,151$ & $21,289,196$ & $695,604,106$ & \\
\hline & $89.5 \%$ & $72.1 \%$ & $18.3 \%$ & $15.5 \%$ & \\
\hline \multirow[t]{2}{*}{$<50$} & $5,753,930$ & $5,882,444$ & $33,190,273$ & $1,094,800,555$ & \\
\hline & $96.2 \%$ & $78.4 \%$ & $28.5 \%$ & $24.4 \%$ & \\
\hline \multirow[t]{2}{*}{$<100$} & $5,878,784$ & $6,088,533$ & $41,733,545$ & $1,396,057,509$ & \\
\hline & $98.2 \%$ & $81.2 \%$ & $35.9 \%$ & $31.1 \%$ & \\
\hline \multirow[t]{2}{*}{$<500$} & $5,966,069$ & $6,420,532$ & $58,644,585$ & $2,012,581,741$ & \\
\hline & $99.7 \%$ & $85.6 \%$ & $50.4 \%$ & $44.9 \%$ & \\
\hline & & & & & \\
\hline & & & & & \\
\hline
\end{tabular}

Moreover, it is estimated that small businesses account for 14 times as many patents per employee as do large organizations, and their patents are twice as likely to rank among the $1 \%$ of most cited patents. Clearly, this is a vibrant market, one that is likely to attract the interest of the Millennial Generation (Gen-Y) that is poised to enter the workplace in force. The question is whether b-schools are preparing graduates for this alternative.

Small and medium-sized enterprises (SMEs) differ from public corporations in several important ways. In particular, SMEs do not issue equity that is traded in secondary markets, and therefore do not have a direct measure of systematic risk (beta). Because both the SME owners and the enterprise projects are less diversified, the market is likely to price much of the unsystematic risk. There are fewer agency issues, in that the owner also tends to be directly involved in operations, there tend to be fewer slack resources than within a corporate setting, and a single project may represent much or all of the enterprise. However, traditional business school courses and textbooks 
assume a goal of maximizing stock price, emphasize that much of risk is diversifiable and therefore not priced by the market, explain in detail the conflicts inherent in separation between ownership and management, and so on.

\section{How SMEs Differ from Publicly-traded Corporationss:}

- Market Prices

- Corp. Risk Measures

- Risk Diversification

- Agency Issues

- Slack Resources

- Scale and Integration
$\mathbf{P}_{0}=\mathrm{D}_{1} /(\mathrm{k}-\mathrm{g})$

$k_{e}=r_{f}+\beta\left(r_{m}-r_{f}\right)$

$\sigma^{2} \gg \beta$

Owner $\approx$ Management

Lean Operations

Project $\approx$ Enterprise

It would be less a problem if these ideas were malleable, and could be modified to fit a small business. Unfortunately, in most cases that is not the case. Here is one example.

\section{An Example}

The first formula above values a corporation by discounting its expected dividend payment next year by the differential between its cost of capital and its anticipated (constant) growth rate. Leaving aside the need to substitute a different numerator, how might a small business estimate its cost of capital? The second formula work fine for a public-traded corporation, but there is no market-based beta for a small business. What could we be teaching students in our business classes? One idea would be to introduce the notion of "accounting betas", and to derive the cost of capital from such estimates. Another idea would be to derive an estimate from the most basic of building blocks - the risk-free rate and the probability of firm survival. Following Cheung (1), letting $p=$ the one-period probability of survival, and letting $\mathrm{r}=$ the risk-free rate, then the one-period implied cost of capital, $\mathrm{k}$, for a firm with no debt equals:

$\mathrm{k}=[(1+\mathrm{r}) / \mathrm{p}]-1$

$=(\mathrm{r} / \mathrm{p})+(1-\mathrm{p}) / \mathrm{p}$

How can this simple measure be applied to a small business? Consider the following graph published by the SBA (2), which plots survival rates after x years, by industry: 


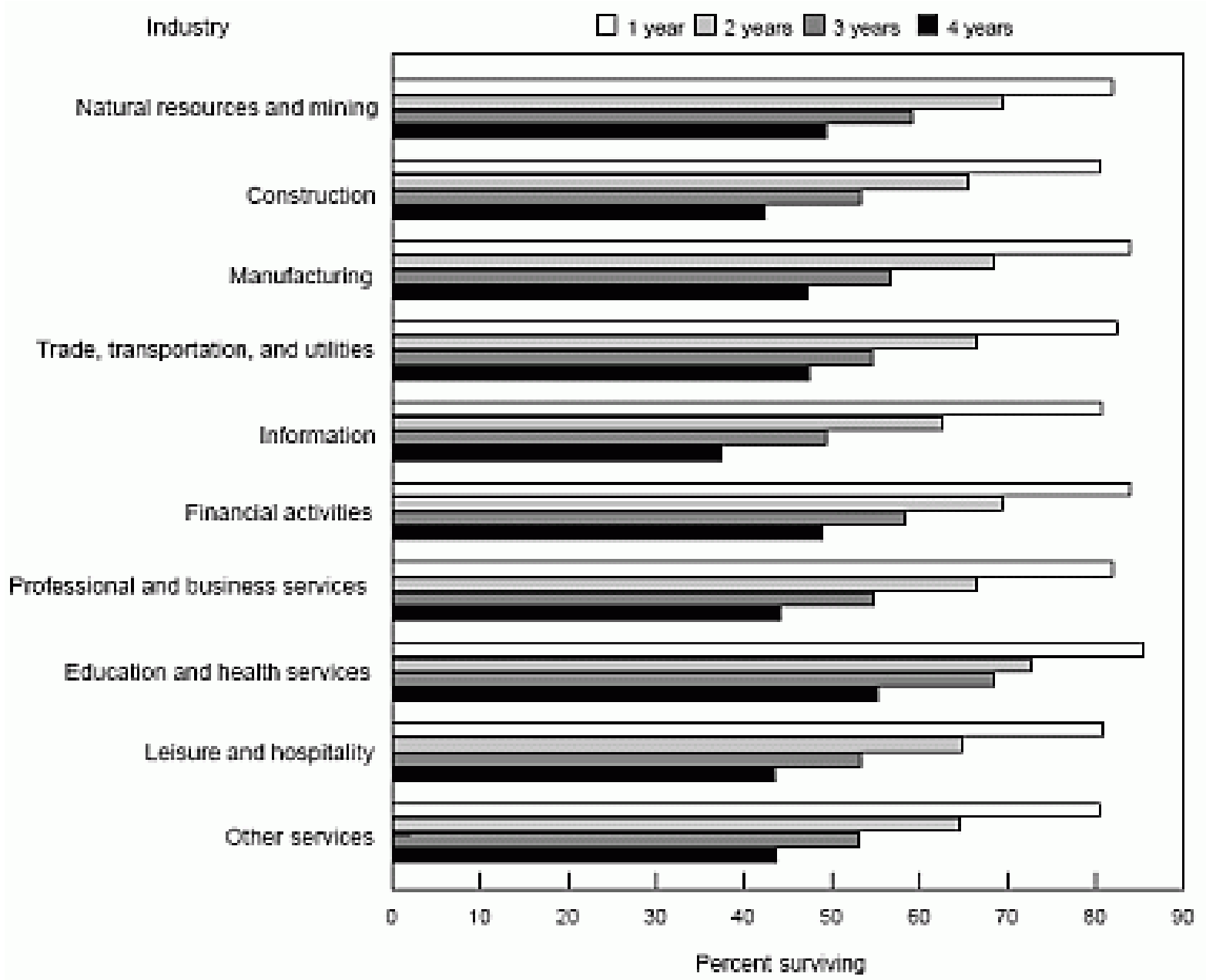

Inferring numeric survival probabilities from year $(\mathrm{x}-1)$ to year $\mathrm{x}$ from the graph:

http://www.smallbiztrends.com/2005/07/business-failure-rates-highest-in.html

\begin{tabular}{|c|c|c|c|c|c|c|c|c|c|c|}
\hline & & Constr & Manuf & Trade.Tr \& U & Info Sys & Fin Sery & Pers/Bus Serv & Educ \& Health & Leisure \& Hosp & Other Services \\
\hline 1 & 0.82 & 0.80 & 0.85 & 0.83 & 0.80 & 0.85 & 0.82 & 0.87 & 0.81 & 0.81 \\
\hline 2 & 0.68 & 0.65 & 0.68 & 0.67 & 0.62 & 0.69 & 0.67 & 0.74 & 0.65 & 0.64 \\
\hline 3 & 0.59 & 0.54 & 0.57 & 0.54 & 0.49 & 0.58 & 0.55 & 0.68 & 0.54 & 0.53 \\
\hline 4 & 0.49 & 0.42 & 0.47 & 0.47 & 0.37 & 0.49 & 0.45 & 0.56 & 0.44 & 0.44 \\
\hline
\end{tabular}

Cumulative annualized survival rates after $\mathrm{x}$ years can be constructed for each industry:

\begin{tabular}{|lllllllllll|}
\hline \multicolumn{2}{|c|}{ NR\&M } & Constr & Manuf & Trade. Tr \& U & Info Sys & Fin Serv & \multicolumn{1}{c|}{ Pers/Bus Serv Educ \& Health Leisure \& Hosp Other Services } \\
1 & 0.820000 & 0.800000 & 0.850000 & 0.830000 & 0.800000 & 0.850000 & 0.820000 & 0.870000 & 0.810000 & 0.810000 \\
2 & 0.824621 & 0.806226 & 0.824621 & 0.818535 & 0.787401 & 0.830662 & 0.818535 & 0.860233 & 0.806226 & 0.800000 \\
3 & 0.838721 & 0.814325 & 0.829134 & 0.814325 & 0.788374 & 0.833955 & 0.819321 & 0.879366 & 0.814325 & 0.809267 \\
4 & 0.836660 & 0.805030 & 0.827989 & 0.827969 & 0.779921 & 0.836660 & 0.819036 & 0.865062 & 0.814448 & 0.814448 \\
\hline
\end{tabular}

The inferred cost of capital (k) for each year can then be estimated:

\begin{tabular}{|c|c|c|c|c|c|c|c|c|c|c|}
\hline & NR\&M & Constr & Manuf & Trade, Tr \& U & Info Sys & Fin Serv & Pers/Bus Sen & Educ \& Health & Leisure \& Hosp & Other Se \\
\hline 1 & 0.268293 & 0.300000 & 0.223529 & 0.253012 & 0.300000 & 0.223529 & 0.268293 & 0.195402 & 0.283951 & 3951 \\
\hline 2 & 0.261185 & 0.289961 & 0.261185 & 0.270562 & 0.320801 & 0.252013 & 0.270562 & 0.208975 & 0.289961 & 0000 \\
\hline 3 & 0.239984 & 0.277131 & 0.254320 & 0.277131 & 0.319172 & 0.247070 & 0.269343 & 0.182670 & 0.277131 & 5113 \\
\hline 4 & 0.243038 & 0.291877 & 0.256056 & 0.256056 & 0.333469 & 0.243038 & 0.269785 & 0.202227 & 0.276939 & 0.276939 \\
\hline
\end{tabular}


Finally, the median cost of capital over time can be used to approximate the appropriate discount rate to apply for a small business in a given industry:

\begin{tabular}{|c|c|c|c|c|c|c|c|c|c|c|}
\hline & NR\&M & Constr & Manuf & Trade.Tr \& U & Info Sys & Fin Serv & Pers B & Educ \& Hea & Leisure \& H & Other Sen \\
\hline & $25.2 \%$ & $29.1 \%$ & $25.5 \%$ & $26.3 \%$ & $32.0 \%$ & $24.5 \%$ & $27.0 \%$ & $19.9 \%$ & $28.1 \%$ & $28.5 \%$ \\
\hline
\end{tabular}

These imputed discount rates vary from the least risky industry (education and health, at $19.9 \%$, to the most risky industry (information systems, at $32.0 \%$ ).

There may be better strategies to estimate the cost of capital for a small business; certainly, there are refinements to the above strategy that would improve estimates in a multi-period setting, especially if the firm has substantial debt outstanding. The important points here are that: (i.) textbook strategies for estimating cost of capital often are inappropriate for strategies do exist for small businesses, (ii.) alternative strategies to estimating cost of capital for a small business do exist, (iii.) the need for alternative strategies in dealing with small businesses extends well beyond cost of capital estimation to a variety of other issues in business modeling, and (iv.) the needs also extend beyond small businesses to other non-traded enterprises. B-schools are choosing to not address these needs, but competitive pressures and market dynamics will force the issue. Most operate in the lower right corner of the table below, largely ignoring columns to the left.

\section{Taxonomy of Enterprises}

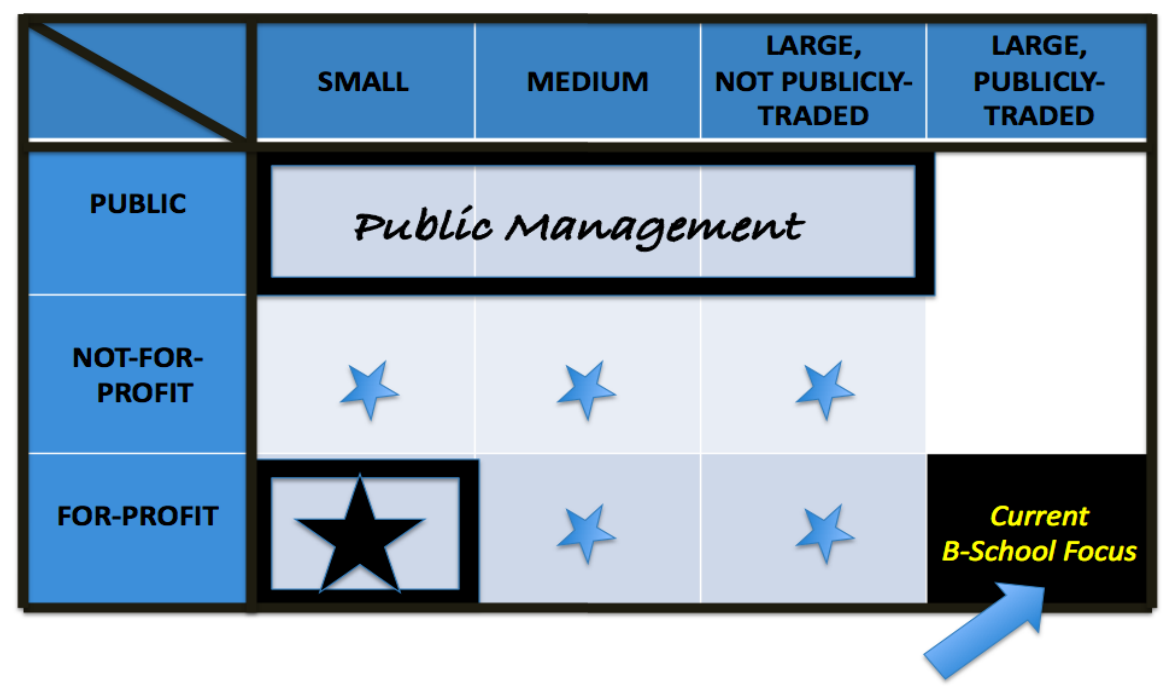

\section{SPATIAL AWARENESS}

Everything exists in both time and space. It is routine practice to incorporate the temporal perspective in business curriculum, sometimes by analyzing financial statements over time, sometimes looking for historical patterns in consumer behavior, often times doing more sophisticated forms of time-series analysis. Why isn't space afforded the same treatment? I think the old answer is that it was simply too hard to do well, and the new answer is that most business faculty are unaware of the tremendous advances in technology through geographic information systems (GIS), in methodology relating to spatial econometrics, and especially in sophisticated applications - which many companies guard with some secrecy as a perceived competitive advantage. 
Spatial awareness begins with the injection of spatial data into an existing database:

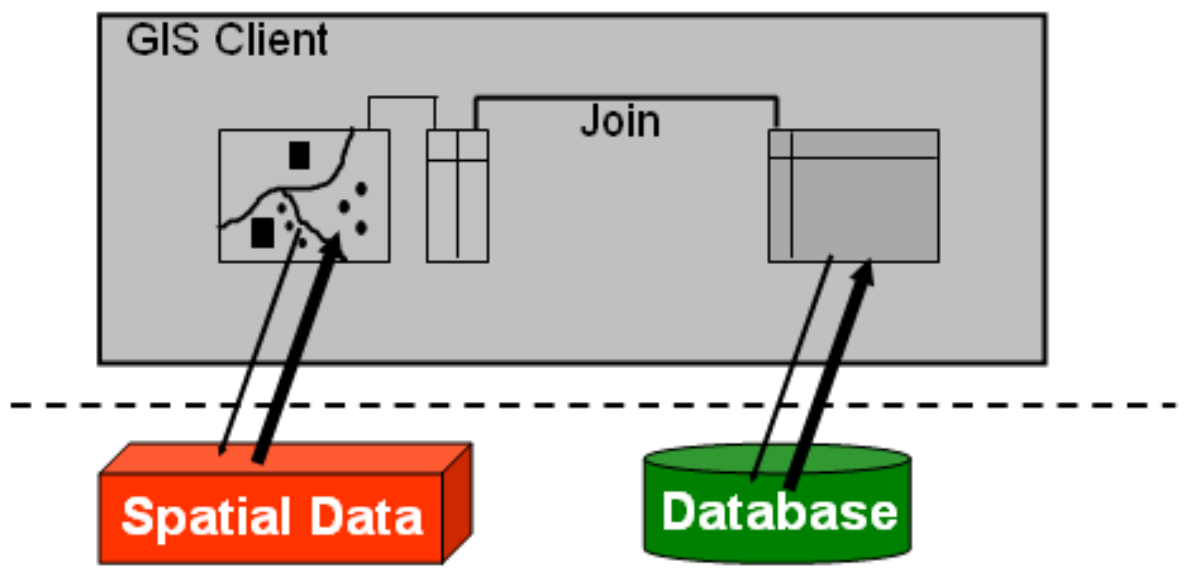

The physical space of interest can serve as a data terrain of sorts, upon which multiple layers of information can be superimposed. Any region of the terrain can be drilled to whatever depth is of interest and variations among layers as one explores the terrain can be observed, measured, and modeled. Spatial autocorrelation is the counterpart to time-series autocorrelation, and can reveal new patterns, suggest hypotheses, identify deficiencies in models assuming independence among observations, and guide us toward alternative formulations. Students appreciate that spatial analysis also is highly intuitive.

\section{An Example}

Assume you are a company marketing Brand X Cola throughout the United States. By what generic name do you refer to your product? Following (3) is the first several rows of data pertaining to frequency of term usage, by state, for a sample of many consumers:

\begin{tabular}{|c|r|r|r|r|r|r|}
\hline State/Province & pop & soda & coke & other & \multicolumn{1}{l|}{ Total } & \multicolumn{1}{|l|}{$\mid$} \\
\hline Total & 102148 & 95169 & 42420 & 17154 & 256891 & $100.00 \%$ \\
\hline United States & 90463 & 92318 & 40779 & 15523 & 239083 & $93.07 \%$ \\
\hline Alabama & 22 & 252 & 2110 & 196 & 2580 & $1.00 \%$ \\
\hline Alaska & 234 & 295 & 35 & 56 & 620 & $0.24 \%$ \\
\hline American Samoa & 7 & 7 & 1 & 16 & 31 & $0.01 \%$ \\
\hline Arizona & 373 & 1496 & 327 & 129 & 2325 & $0.91 \%$ \\
\hline Arkansas & 88 & 169 & 1007 & 48 & 1312 & $0.51 \%$ \\
\hline California & 658 & 12484 & 2257 & 5989 & 21388 & $8.33 \%$ \\
\hline Colorado & 2000 & 1012 & 254 & 124 & 3390 & $1.32 \%$ \\
\hline Connecticut & 47 & 2867 & 79 & 94 & 3087 & $1.20 \%$ \\
\hline Delaware & 17 & 483 & 33 & 11 & 544 & $0.21 \%$ \\
\hline District of Columbia & 28 & 300 & 43 & 27 & 398 & $0.15 \%$ \\
\hline \hline
\end{tabular}


Insights are not immediately forthcoming for most of us when looking at a table of more than fifty rows of such data. With some effort, and with the help of a spreadsheet, we can determine that most Californians (58.4\%) in the survey prefer the term "soda", whereas few (3.1\%) prefer the term "pop" - even though these two terms are used about equally when preferences are aggregated across all fifty states. Clearly there are differences among states. Are these differences clustered by region, or randomly spread across the nation? That is not easily or quickly discerned from the table, not even with a spreadsheet. Now, let's map similar results, which is the most basic GIS application:

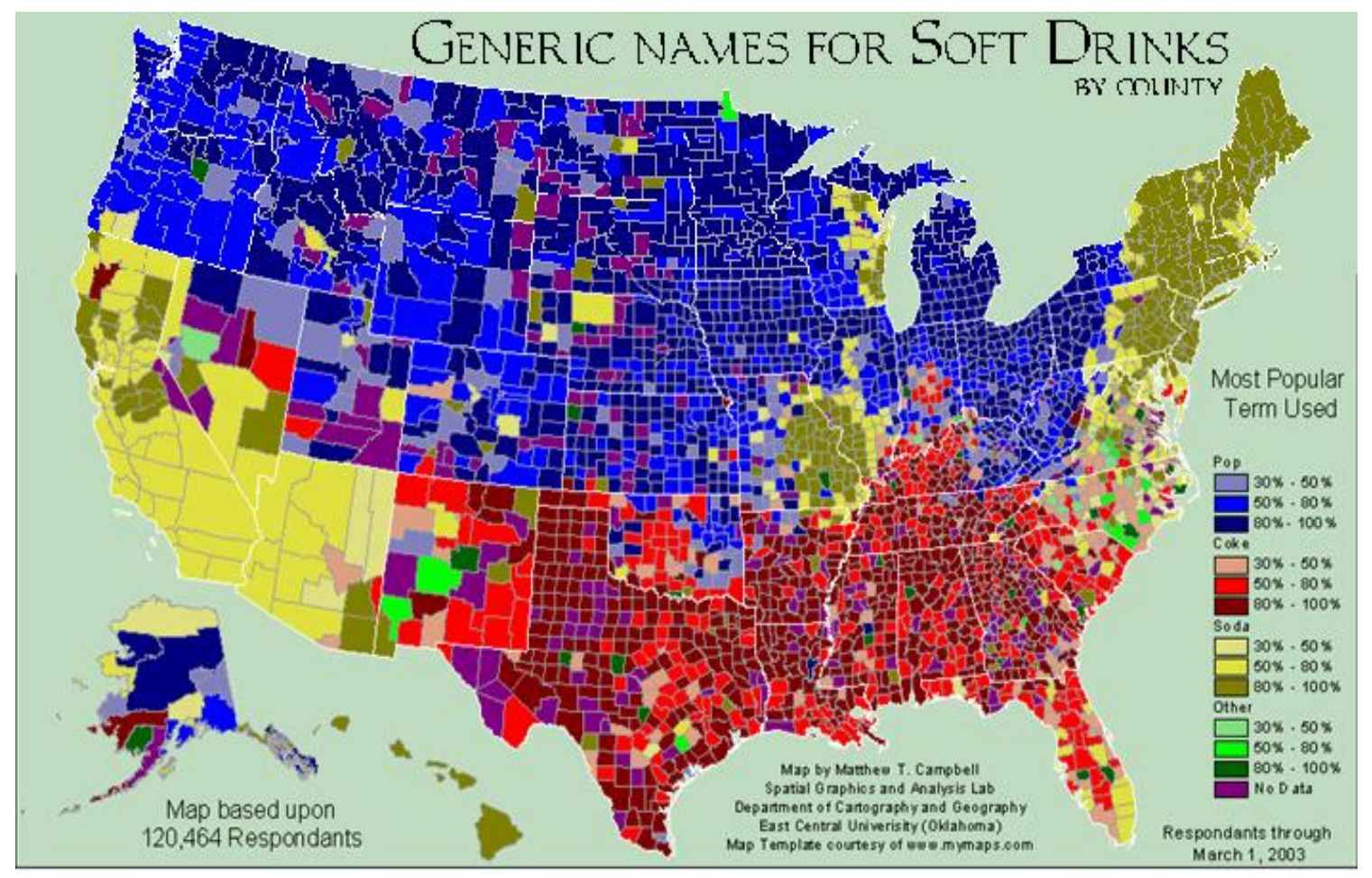

Regional clustering is immediately evident: the preferred term when marketing in the South is "coke", and in the Midwest is "pop". More subtle differences also are revealed.

Spatial awareness, then, is an opportunity to see new relationships, and to see known relationships in new ways. Realistic applications layer not just one attribute (term preference) on a map, but simultaneously present multiple layers of attributes. Such a rich information environment provides opportunities for more rich insights and analyses. 


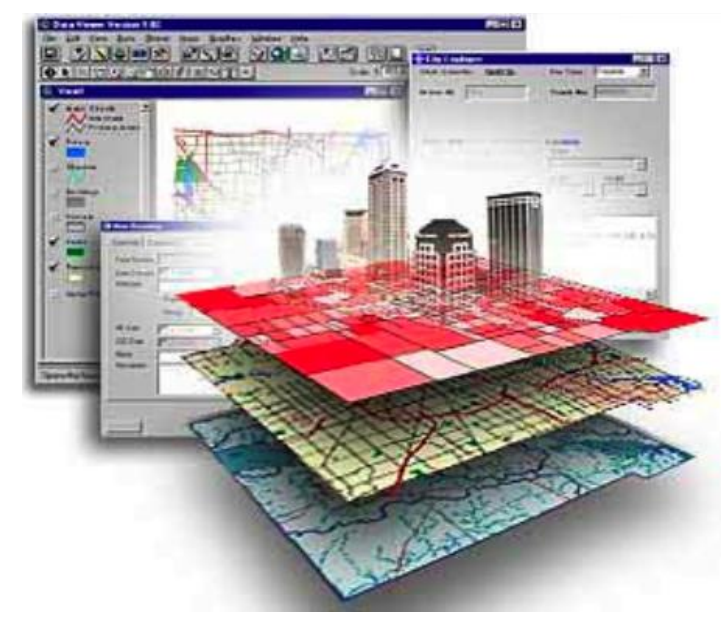

\section{CONCLUSIONS}

Business school accreditation and competitive pressures both assert pressure for continuous improvement, suggesting change in curricula is likely with each generation. Your guesses of the next waves in change may be different than mine, and may be more accurate. The current rage is sustainability, or "Green MBAs", which now face its own sustainability test in the aftermath of the financial meltdown of 2008. One reason I'm inclined toward the two waves I have discussed is practical - many existing faculty can make parallel shifts in emphasis without much retooling. For example, many specialists in management strategy would have little difficulty refocusing on alternative objective functions to stock price maximization, and the consequences. Likewise, many current faculty in management information systems are well-positioned to move into GIS. To the extent a business school facilitates such shifts, it should gain competitive advantage.

\section{AUTHOR INFORMATION}

Dr. Platt was recipient of the first doctoral degree awarded by what is now the John Glenn School of Public Affairs at the Ohio State University. Dr. Platt spent the next two decades as a faculty member of the College of Business at San Francisco State University, and in 2000 was named dean. In 2004 he left that position to become the inaugural holder of the Senecal Endowed Deans' Chair in the School of Business at the University of Redlands. Two years later, the School received a major grant from the SBA and Dr. Platt stepped away from the deanship to direct the grant.

\section{REFERENCES}

(1) Cheung, J., A Probability-Based Approach to Estimating Costs of Capital for Small Business, Small Business Economics, 12: 331-336, 1999

(2) U.S. Government Printing Office, The Small Business Economy: A Report to the President, 2007

(3) Von Schneidemesser, L., Soda or Pop?, Journal of English Linguistics. December 1996 (see also: http://popvssoda.com:2998/). 